\title{
Assessment of Genetic Diversity in New Restorer Lines of Hybrid Rice
}

\author{
P. Jeevanapriya ${ }^{1}$, R. Saraswathi ${ }^{1 *}$, V. Thiruvengadam ${ }^{2}$ and K. Krishna Surendar ${ }^{1}$ \\ ${ }^{1}$ Department of Rice, Centre for Plant Breeding and Genetics, Tamil Nadu Agricultural \\ University, Coimbatore - 03, Tamilnadu, India \\ ${ }^{2}$ Department of Plant Genetic Resources, Centre for Plant Breeding and Genetics, Tamil \\ Nadu Agricultural University, Coimbatore - 03, Tamilnadu, India \\ *Corresponding author
}

\section{A B S T R A C T}

Ke y w o r d s
Rice restorer lines,
PCA, Genetic
diversity, Eigen
values

\section{Keywords}

Rice restorer lines, PCA, Genetic diversity, Eigen Article Info

Accepted: Available Online: 10 July 2019
A population panel comprising 126 newly developed restorer lines that can be utilized in hybrid rice breeding in future were evaluated for 16 agro-morphological and grain quality traits by principal component analysis for determining the pattern of genetic diversity and relationship among individuals. Agro- morphological traits included days to fifty per cent flowering, plant height, productive tillers, basal internode thickness, culm strength, flag leaf length, panicle length, number of filled grains per panicle, panicle exsertion, panicle secondary branching, spikelet fertility, 100 seed weight, single plant yield and grain quality traits were kernel length, kernel breadth and kernel LB ratio. The cumulative variance of $70.20 \%$ was explained by six principal components. Component 1 had the contribution from the traits viz., productive tillers, culm strength, spikelet fertility, kernel length and panicle secondary branching which accounted $15.79 \%$ of the total variability. The remaining variability of $14.81 \%, 12.10 \%, 11.75 \%, 9.44 \%$ and $6.31 \%$ was consolidated in component 2, component 3, component 4, component 5 and component 6 respectively. The grain quality traits viz., kernel length, kernel breadth and kernel LB ratio were loaded as major traits in PC6, PC5 and PC4 respectively. The trait single plant yield was the predominant trait in component 6 . The results of present study identified the key economic traits, which accounts for maximum variation in the restorer lines under study which will be greatly beneficial to exploit in the hybrid rice breeding programmes.

\section{Introduction}

Rice (Oryza sativa L.) is a staple food crop that provides the primary source of calories for more than 50 per cent of the world's population. Over 90 per cent of the world's rice is produced and consumed in the Asian Region with six countries (China, India, Indonesia, Bangladesh, Vietnam and Japan) that account for $80 \%$ in the world's production and consumption (Abdullah, 2006). The United Nations estimates predict that, global population will increase $33 \%$ by 2050 , from 7.2 billion today to 9.6 billion persons. To feed the ever-increasing human population, yield potential of rice should also be improved through evolution of high yielding varieties and hybrids which could be realized by 
exploiting the genetically diverse breeding materials.

In this context, assessment of genetic diversity plays a definitive role to select genotypes that can be used as parents in three line hybrid breeding programme inclusive of the presence of fertility restorer genes for WA- CMS currently exploited. A set of new parental lines were developed through recombination breeding and selection from restorer $\mathrm{x}$ restorer crosses of TNAU and IRRI, restorer $\mathrm{x}$ tropical japonica or vice-versa from TNAU. The presence of fertility restorer genes either $R f 3$ or Rf4 or both for Wild Abortive -CMS was confirmed by molecular marker analysis. Thus the objective of the present study was to ascertain the genetic diversity through principal component analysis for agronomic and grain quality traits in the stabilized breeding lines to exploit them in hybrid rice breeding to realize the genetic gains.

\section{Materials and Methods}

In the present study, 126 restorer lines of rice were raised in augmented design with three checks viz., CO (R) 50, CO 51, CO 52 during kharif 2018 at Department of Rice, Centre for Genetics and Plant Breeding, Tamil Nadu Agricultural University, Coimbatore. Each entry was planted at a spacing of $20 \mathrm{~cm} \times 15$ $\mathrm{cm}$ and the recommended agronomic practices were followed. Observations on 13 agronomic and yield contributing traits viz., days to fifty per cent flowering, plant height $(\mathrm{cm})$, productive tillers (no.), basal internode thickness $(\mathrm{mm})$, culm strength $(\mathrm{g} / \mathrm{stem})$, flag leaf length $(\mathrm{cm})$, panicle length $(\mathrm{cm})$, number of filled grains per panicle, panicle exsertion, panicle secondary branching (no.), spikelet fertility (\%), 100 seed weight (g), single plant yield $(\mathrm{g})$ and three grain quality traits viz., kernel length $(\mathrm{mm})$, kernel breadth $(\mathrm{mm})$ and $\mathrm{L} / \mathrm{B}$ ratio were recorded in randomly selected five plants (SES, IRRI, 2013) except days to
$50 \%$ flowering. The culm strength was measured and calculated as quoted by Hai et al., (2005). Principal component analysis was performed by using STAR (Statistical Tools for Agricultural Research) software. Eigen vectors were calculated by using the following formula-

Percentage of variance explained for $P C 1=\frac{\text { Eigen value of } \mathrm{PC1}}{\text { Sum of } 1 \text { igen values }}$

The cumulative percentage of contribution to variation of different traits to eigen vectors were also computed.

\section{Results and Discussion}

Principle component analysis is one of the important tools of genetic diversity analysis. It is a multivariate statistical technique employed to identify the minimum number of components that explain maximum variability out of the total variability present in the breeding material analyzed. It is also used to rank the genotypes based on PC scores (Anderson, 1972 and Morrison, 1967).

Thus, the technique is very helpful for identification of plant characters that are categorized for their distinctiveness among promising genotypes. Eigen values measure the importance and contribution of each component to total variance whereas each coefficient of eigen vectors indicates the degree of contribution of every original variable with which each principal component is associated. The higher the coefficients, regardless of the sign, the more effective will be the discriminating power between accessions (Clifford and Stephenson, 1975). According to Kaiser (1960), each principal component with Eigen value greater than one could be considered to contribute at least $10 \%$ of the phenotypic variation. The higher Eigen values were considered as best representative of system attributes in principal components. 
In our present study, the results of PCA explained the genetic variation among the genotypes for all agro morphological and quality characters under study. The analysis revealed six components with Eigen value more than one and explained a cumulative variation of $70.20 \%$. The PC 1 which showed $15.79 \%$, the highest variability among traits had an Eigen value of 2.52 (Table 1). Scree plot explained the percentage of variation associated with each principal component obtained by drawing a graph between Eigen values and principal component numbers (Figure 1). The Eigen values gradually declined. Elbow type line was shifted to straight line with minute difference with each PC value after principal component 6 . Accordingly, PC2, PC3, PC4, PC5 and PC6 exhibited $14.81 \%, 12.10 \%, 11.75 \%, 9.44 \%$ and $6.31 \%$ variability respectively. In previous investigations on principal component analysis in rice germplasm, formation of six principal components as encountered in our present study was also reported by Ojha et al., (2017), Pathak et al., (2018) and Suneetha et al., (2018) in 207, 98 and 95 genotypes for 17, 13 and 20 traits respectively. However with as few as 24 rice varieties, Kunusoth et al., (2015) obtained seven components for 24 traits. Hasan et al., (2012) performed $\mathrm{D}^{2}$ and PCA analysis in 30 restorer and 10 maintainer lines of rice in which two principal components were derived. In 100 restorer and maintainer lines, 10 clusters were formed in cluster analysis by coefficient of parentage (Wang et al., 2012) of which, the restorer lines further divided into 11 sub clusters.

The results on Eigen vectors of 16 agromorphological traits are presented in Table 2 and Figure 2. Rotated component matrix revealed that PC1 was highly loaded with characters such as productive tillers (0.469), culm strength (-0.430), spikelet fertility (0.325), kernel length (-0.303) and panicle secondary branching (-0.259). The component
PC2 accounted for $14.81 \%$ variation which was contributed by characters viz., plant height $(-0.379)$, culm strength $(-0.372)$, productive tillers (0.339), panicle length (-0.328) and flag leaf length (-0.302).

The traits like single plant yield (0.409), panicle length (-0.398), spikelet fertility (0.388), days to $50 \%$ flowering (-0.377), flag leaf length $(-0.367)$, plant height $(-0.344)$ in PC3 contributed for $12.10 \%$ variation. The fourth principal component was loaded by major traits like kernel length breadth ratio (0.604), kernel length (-0.398), kernel breadth (0.383), number of filled grains per panicle (0.376), 100 seed weight (-0.293) and panicle exsertion (-0.269) that accounted for $11.75 \%$ of the variation. The variation explained by both PC3 and PC4 was almost equal.

It was observed that the characters viz., kernel breadth (0.433), panicle exsertion (0.416), days to $50 \%$ flowering (-0.323), kernel length breadth ratio $(-0.314)$, basal internode thickness (-0.287), panicle secondary branching (-0.274) contributed to the $9.4 \%$ of variation in PC5. The least variation of $6.31 \%$ accounted in PC6 were contributed by the traits kernel breadth (-0.505), 100 seed weight (0.434), days to $50 \%$ flowering (0.304), plant height (0.292), number of filled grains per panicle (0.298), kernel breadth (-0.283), basal internode thickness (0.259) and panicle secondary branching $(-0.240)$.

In the studies of Sathish et al., (2017) and Gour et al., (2017), the number of productive tillers was loaded in PC1 as realized in our analysis. So also, similar type of loading in PC1 for kernel length was reported by Mengli et.al (2017). The traits viz., basal internode thickness and leaf length loaded in PC5 (9.4\% variability) and PC3 (12.1\% variability) respectively in the present investigation was realized by Kunusoth et al., (2015) in PC1explaining $18.32 \%$ of the variability. 
Table.1 Eigen value and contribution of variability in 126 rice restorer lines

\begin{tabular}{|c|c|c|c|c|c|c|c|}
\hline S.No. & Principal components (PCs) & $\mathbf{1}$ & $\mathbf{2}$ & $\mathbf{3}$ & $\mathbf{4}$ & $\mathbf{5}$ & $\mathbf{6}$ \\
\hline $\mathbf{1 .}$ & Eigen value & 2.526 & 2.370 & 1.935 & 1.880 & 1.510 & 1.009 \\
\hline $\mathbf{2 .}$ & Variability (\%) & 15.79 & 14.81 & 12.10 & 11.75 & 9.44 & 6.31 \\
\hline $\mathbf{3 .}$ & Cumulative\% & 15.79 & 30.60 & 42.70 & 54.45 & 63.89 & 70.20 \\
\hline
\end{tabular}

Table.2 Eigen vectors of 16 agro-morphological traits in rice restorer lines

\begin{tabular}{|c|c|c|c|c|c|c|c|}
\hline S.No. & Traits & \multicolumn{5}{|c|}{ Eigen vectors } \\
\hline $\mathbf{1 .}$ & Days to 50\% flowering & -0.087 & 0.065 & -0.377 & 0.194 & -0.324 & 0.305 \\
\hline $\mathbf{2 .}$ & Plant height & 0.149 & -0.380 & -0.345 & -0.049 & 0.001 & 0.293 \\
\hline $\mathbf{3 .}$ & Productive tillers & 0.470 & 0.340 & -0.065 & -0.016 & 0.122 & -0.027 \\
\hline $\mathbf{4 .}$ & Basal internode thickness & -0.209 & -0.029 & 0.021 & -0.214 & 0.288 & 0.259 \\
\hline $\mathbf{5 .}$ & Flag leaf length & 0.090 & -0.303 & -0.367 & -0.067 & -0.035 & -0.274 \\
\hline $\mathbf{6 .}$ & Panicle length & 0.218 & -0.329 & -0.399 & -0.111 & 0.126 & -0.174 \\
\hline $\mathbf{7 .}$ & Number of filled grains per panicle & 0.226 & 0.099 & 0.004 & -0.376 & -0.169 & 0.298 \\
\hline $\mathbf{8 .}$ & Panicle exsertion & 0.177 & -0.039 & -0.209 & -0.269 & 0.416 & -0.034 \\
\hline $\mathbf{9 .}$ & Panicle secondary branching & -0.260 & -0.009 & -0.076 & 0.202 & -0.274 & -0.240 \\
\hline $\mathbf{1 0 .}$ & Culm strength & -0.434 & -0.372 & -0.043 & -0.006 & -0.147 & 0.107 \\
\hline $\mathbf{1 1}$ & Kernel length & -0.304 & -0.024 & 0.073 & -0.399 & 0.074 & -0.505 \\
\hline $\mathbf{1 2 .}$ & Kernel breadth & -0.148 & -0.260 & 0.158 & 0.383 & 0.433 & -0.283 \\
\hline $\mathbf{1 3}$ & Length breadth ratio & -0.095 & -0.260 & -0.090 & -0.604 & -0.314 & -0.098 \\
\hline $\mathbf{1 4 .}$ & Spikelet fertility & 0.326 & -0.263 & 0.389 & -0.119 & -0.167 & -0.025 \\
\hline $\mathbf{1 5}$ & 100 seed weight & -0.189 & -0.169 & 0.150 & -0.294 & 0.186 & 0.434 \\
\hline $\mathbf{1 6 .}$ & Single plant yield & 0.216 & -0.327 & 0.410 & -0.113 & -0.124 & 0.125 \\
\hline
\end{tabular}

Fig.1 Scree plot showing Eigen values and percentage of cumulative variability

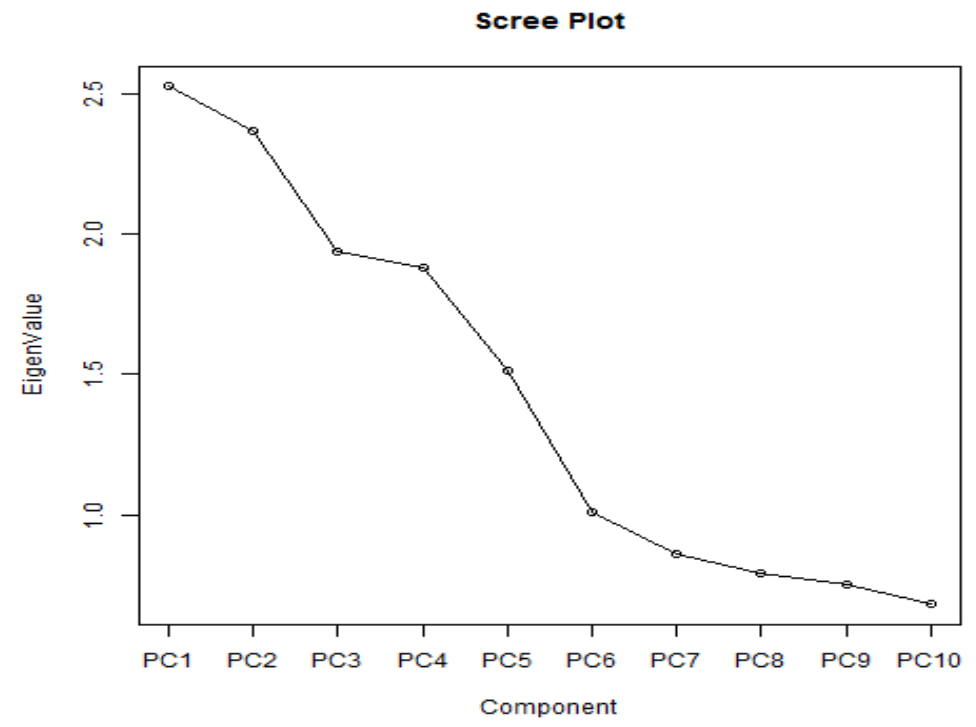


Fig.2 Eigen vectors of 16 agro-morphological traits in rice restorer lines

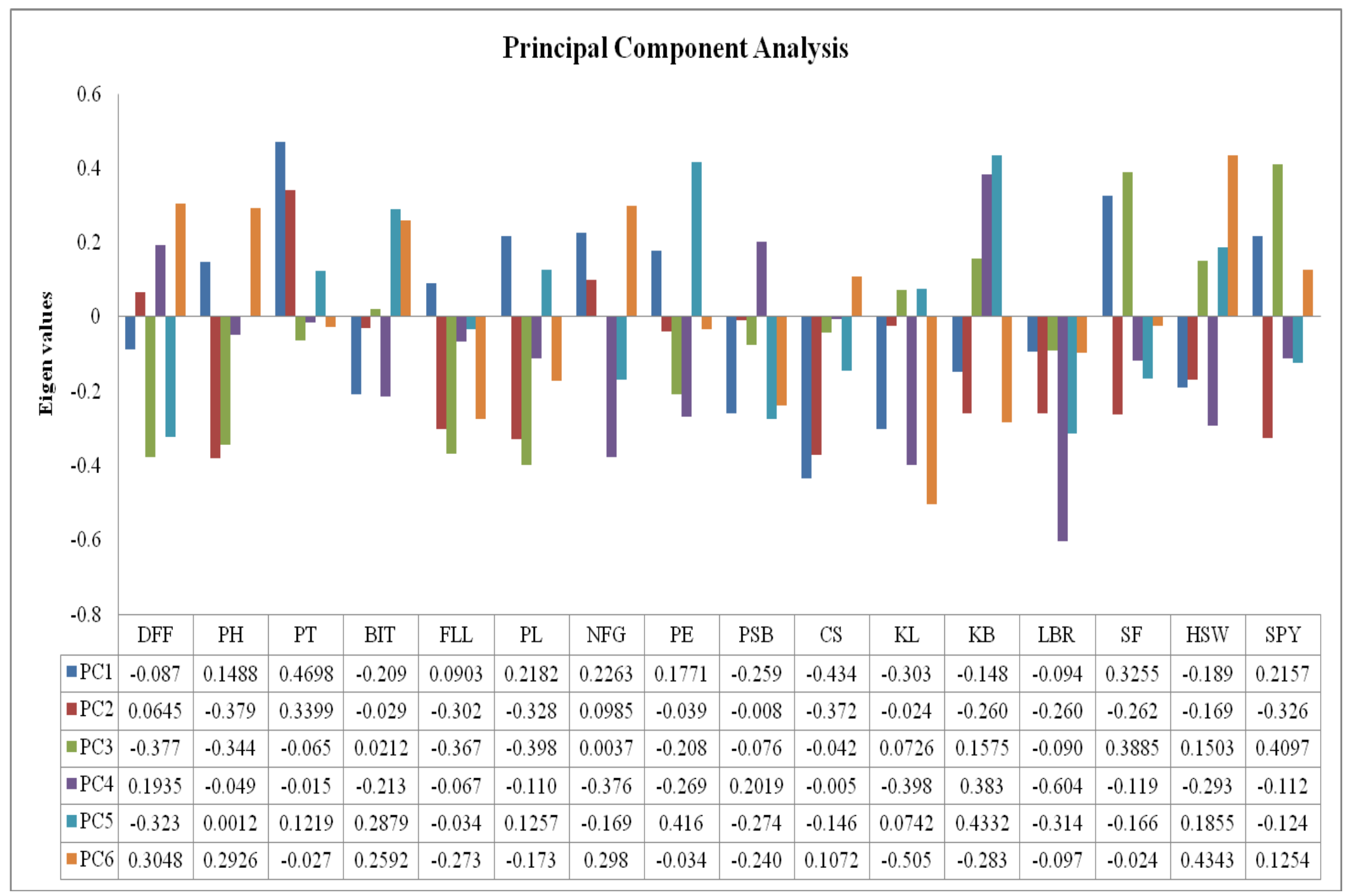


Gana et al., (2013) and Nachimuthu et al., (2014) also published that leaf length was loaded in PC1 explaining $19.1 \%$ and $28.46 \%$ variability respectively.

For the trait 100 grain weight, Gana et al., (2013), Mengli et al., (2017) and Suneetha et al., (2018) reported its loading in PC1 unlike our study in which it was loaded in PC6. Also, kernel breadth that fell in PC5 was reported in PC1 by Sathish et al., (2017).

In contrast to the equal loading of days to $50 \%$ flowering in PC 5 and 6 in our studies, it occupied the first principal component in the publications by Sanni et al., (2012), Nachimuthu et al., (2014), Mahendran et al., (2015), Pachauri et al., (2017) and Suneetha et al., (2018).

For the traits plant height and panicle length that branched off in PC2 and PC 3 was reported by Nachimuthu et al., (2014) and Pachauri et al., (2017) in first component.

Many workers reported number of filled grains in first component unlike fourth component in this investigation.

The ultimate trait single plant yield loaded in PC3 was detected in first component in the experiments of Gour et al., (2017) and Pachauri et al., (2017).

The total variation of $70.20 \%$ observed in the present study is in accordance with the reports of Sanni et al., (2012), Gana et al., (2013), Ojha et al., (2017), Pachauri et al., (2017) and Suneetha et al., (2018) where the variation ranged from 68.86 to $72.48 \%$.

In exceptional cases, high total variation of $92.75 \%$ and $80.56 \%$ were realized by Gour et al., (2017) and Nachimuthu et al., (2014) in their PCA analysis with 33 and 12 traits respectively in 83 and 192 germplasm lines.

In this study, phenotypic traits could be identified which are responsible for the observed genotypic variation present within each component besides traits with maximum variability thus highlighting adequate variability among the restorer lines. These lines with fertility restorer genes for WA- CMS could be utilized to strike at heterotic hybrid combinations in future to realize the yield gains.

\section{References}

Abdullah, Bin, A., Ito, S. and Adhana, K. (2006). Estimate of rice consumption in Asian countries and the world towards 2050. In Proceedings for Workshop and Conference on Rice in the World at Stake, vol. 2, pp. 28-43.

Clifford, Trevor, H., and Stephenson, W. (1975). An introduction to numerical classification. Academic Press.

Gana, A.S., Shaba, S.Z. and Tsado E.K. (2013). Principal component analysis of morphological traits in thirty-nine accessions of rice (Oryza sativa L.) grown in a rainfed low land ecology of Nigeria. Journal of Plant Breeding and Crop Science 5:120-126

Gour, L., Maurya, S.B., Koutu, G.K., Singh, S.K., Shukla, S.S. and Mishra, D.K. (2017). International journal of chemical studies. 5(4):975-983.

Hasan, M. J., Kulsum, U., Rahman, M. M. H., Chowdhury, M. M. H., \& Chowdhury, A. Z. M. K. A. (2012). Genetic diversity analysis of parental lines for hybrid development in rice (Oryza sativa L.). Bangladesh Journal of Agricultural Research, 37(4), 617-624.

Jayasudha, S., and Sharma, D. (2010). Identification of restorers and maintainers for CMS lines of rice (Oryza sativa L.) under shallow low land condition. Electronic Journal of Plant Breeding 1(3): 311-314.

Kaiser, H. F. (1960). The application of electronic computers to factor analysis. Educational and Psychological Measurement. 20: 141-151.

Kunusoth, Keshavulu, Vadivel K., and Meenakshi Sundaram, R. (2015). 
Assessment of genetic diversity of elite Indian rice varieties using agromorphological traits and SSR Markers. American journal of experimental agriculture. 6(6):384-401.

Mahendran, R., Veerabadhiran, P., Robin, S., and Raveendran, M. (2015). Principal component analysis of rice germplasm accessions under high temperature stress. International Journal of Agricultural Science and Research 5(3): 355-359.

Mengli, M., Meng, H., Wang, T. And Lu, B. (2017). Phenotype diversity analysis of red-grained rice land races form Yuanyang Hani's terraced fields, China. In Proceedings for second international Conference on materials science, Resource and Environmental Engineering. 040110:1-5

Morrison and Donald F. (1967). Multivariate Statistical Methods. McGraw-Hill Book Co., New York.

Nachimuthu, Vishnu Varthini, Robin, S., Sudhakar, D., Raveendran, M., Rajeswari, S., and Manonmani, S. (2014). Evaluation of rice genetic diversity and variability in a population panel by principal component analysis. Indian journal of Science and Technology 7(10): 15551562.

Ojha, G. C., Sarawgi, A. K., Sharma, B., and Parikh, M. (2017). Principal component analysis of morpho-physiological traits in rice germplasm accessions (Oryza sativa L.) under rainfed condition. International Journal of Chemical Studies 5, no. 5 (2017): 1875-1878.

Pachauri, A.K., Sarawgi, A.K., Bhandarkar, S. and Ojha, G.C. (2017). Agro- morphological characterization and morphological based genetic diversity analysis of rice (Oryza sativa L.) germplasm. Journal of pharmacognosy and Phytochemistry. 6(6):75-80.

Pathak, S.K., Lavanya, G.R., Babu, G.S. and Srivastava N. (2018). Evaluation of rice germplasm for genetic diversity on yield characters by principal component analysis. The Pharma Innovation Journal 7(4):661-664.

Sanni, K. A., Fawole, I., Ogunbayo, A., Tia, D., Somado, E. A., Futakuchi, K., Sié, M. Nwilene, F. E. and Guei, R.G. (2012). Multivariate analysis of diversity of landrace rice germplasm. Crop Science 52(2): 494-504.

Sathish, V. and Senapti, B.K. (2017). Principal component analysis of morphological and yield attributing trais in advanced breeding lines of rice grown at rainfed shallow low land condition of West Bengal. International journal of biological research and development. 7(3):1-6.

Suneetha, K. (2018).Principal component analysis for agro-morphological and quality characters in germplasm of rice. International journal of advanced and biological research. 8(2):1-5.

T. W. Anderson adn M. A. Stephens (1972). Tests for randomness of directions against equatorial and bimodal alternatives, Biometrika. 59(3):613-621

Wang, S., and Lu, Z. (2006). Genetic diversity among parental lines of Indica hybrid rice (Oryza sativa L.) in China based on coefficient of parentage. Plant Breeding, 125(6), 606-612.

\section{How to cite this article:}

Jeevanapriya, P., R. Saraswathi, V. Thiruvengadam and Krishna Surendar, K. 2019. Assessment of Genetic Diversity in New Restorer Lines of Hybrid Rice. Int.J.Curr.Microbiol.App.Sci. 8(07): 530536. doi: https://doi.org/10.20546/ijcmas.2019.807.065 